\title{
RESOLUÇÃO ALTERNATIVA DE CONFLITOS: ESTRATÉGIA CURRICULAR PARA A FORMAÇÃO INTEGRAL DO SER
}

\author{
AN ALTERNATIVE WAY FOR CONFLICT RESOLUTION: \\ A CURRICULUM STRATEGY FOR INTEGRAL FORMATION
}

\author{
Dione Lorena Tinti ${ }^{1}$ \\ Milene Zanoni da Silva Vosgerau ${ }^{2}$ \\ Denise Cristina Kluge ${ }^{3}$
}

\section{RESUMO}

Este trabalho ${ }^{4}$ discute que para termos um ambiente de paz nos vários níveis da realidade psicossocial, precisamos compreender que a complexidade dos problemas sociais, políticos e ambientais contemporâneos está diretamente vinculada às dificuldades pessoais e sociais de nos relacionarmos e de fazermos escolhas. Temos que incentivar os sujeitos para o "aprender a ser" e o "aprender a viver juntos", que vai bem além de somente "aprender a conhecer" e "aprender a fazer". Assim, o objetivo deste trabalho é relatar a experiência do módulo "resolução alternativa de conflitos" e discutir teórica e metodologicamente os conceitos e práticas da humanização e autoconhecimento inseridos numa proposta de currículo inovador que integra ensino/pesquisa e extensão. Na metodologia, os sujeitos dessa experiência didático-pedagógica são os estudantes e professores da UFPR Setor Litoral e da rede pública do município de Matinhos/PR/Brasil. Além de utilizar um conjunto de conceitos como Cuidado do Ser, Escuta Sensível, Aprender a conhecer, a fazer, a ser e a conviver juntos, a abordagem que nos inspirou foi a teoria junguiana, mais especificamente, o conceito de Sombra. As dinâmicas pedagógicas utilizadas foram teatro, filmes, dinâmicas em grupo, leitura de textos, música e atividades de autoconhecimento. Percebemos que esse exercício permitiu aos envolvidos identificar, compreender e saber lidar com as emoções negativas numa perspectiva sistêmica.

Palavras-chave: Resolução de conflitos; autoconhecimento; estratégia curricular

\section{ABSTRACT}

This study discusses the idea that in order to have a peaceful atmosphere in different levels of the psychosocial reality, we need to understand that the complexity of the social, political and contemporary environments problems are directly related to personal and social difficulties

1 Doutora em Sociologia Política (UFSC), Professora Adjunta na Universidade Federal do Paraná. E-mail: dionetinti@ufpr.br

2 Doutora em Saúde Coletiva (UEL), Professora Adjunta na Universidade Federal do Paranál/PR. E-mail: milenezanoni@gmail.com

3 Doutora em Letras/Inglês (UFSC), Professora Adjunta da Universidade Federal do Paraná, PR. E-mail: deniseckluge@gmail.com

4 Este trabalho foi apresentado na forma de banner no XI Congresso Iberoamericano de Extension Universitaria que aconteceu entre 21 e 25 de novembro de 2011, em Santa Fé, Argentina.

Divers@ Revista Eletrônica Interdisciplinar/Matinhos/Vol.5, n.1/p.1-92|/jan./jun.2012 
we face in our relationships as well as in our choices. We should motivate people to learn "how to be" and "how to live together" which is beyond the idea of learning "how to know" and "how to do". Therefore, the main objective of this study is to report the practice experienced during a course called "An alternative way for conflict resolution", as well as to discuss theoretical and methodological concepts, practices of humanization and selfknowledge inserted in a new curriculum project which integrates teaching, research and science outreach. The participants of this study are undergraduate students and professors from Federal University of Paraná - Litoral Campus and a teacher from a public school in Matinhos- Paraná. During the classes we discussed issues/concepts such as taking care; sensitive listening; learning how to know, to do, to be and to live together; besides the Shadow concept by Yung. The pedagogical strategies used were drama/theater practices, movies, group dynamics, articles reading, songs and self-knowledge activities. By observing the classes and the participants' practices we noticed that, in general, the activities allowed the participants to identify, understand and learn how do deal with their negatives feelings/emotions through a systemic perspective.

Keywords: alternative way for conflict resolution; self-knowledge; curriculum strategy

"Tu me dizes, eu esqueço.
Tu me ensinas, eu lembro.
Tu me envolves, eu prendo".
Benjamim Franklin
"As pessoas têm medo do que há dentro delas, mas é o único lugar
onde irão achar o que precisam".
Filme: Poder além da vida

\section{Introdução}

O Setor Litoral da Universidade Federal do Paraná (UFPR), localizado em Matinhos no Estado do Paraná, Brasil, vem buscando adotar um modelo de educação compatível com as demandas locais contemporâneas assumindo o desafio de exercitar o seu papel social de questionador crítico e fomentador de conhecimentos que dialoguem com a realidade social e econômica em que se insere (PPP, 2008).

Docentes de diversas áreas do conhecimento, em uma abordagem multidisciplinar, por meio de currículo em movimento, vêm buscando formação diferenciada por meio de um Projeto Político Pedagógico (PPP) que é norteado por três eixos curriculares articulados entre si: Fundamentos Teórico-Práticos (FTPs), Projetos de Aprendizagem ${ }^{5}$ (PA) e Interações Culturais e Humanísticas (ICH) ${ }^{6}$.

5 Não há um conceito definitivo do que é Projeto de Aprendizagem (PA), mas a ideia que o fundamenta na UFPR Litoral é que "a escolha do tema deve representar o interesse, exclusivamente, do estudante"

Divers@Revista Eletrônica Interdisciplinar/Matinhos/Vol.5, n.1/p.1-92//jan./jun.2012 
No espaço FTPs foi desenvolvida a experiência descrita no presente artigo. Esse eixo pedagógico faz parte do currículo de todos os acadêmicos do Setor e com carga horária semanal de 12 horas distribuídas em três módulos de quatro horas cada, os estudantes entram em contato com os conceitos e práticas específicas de seu curso. Esse espaço pedagógico sustenta e permeia o processo de ensino-aprendizagem focado na formação humana, técnica e científica.

O curso de Saúde Coletiva, como curso estratégico da UFPR Setor Litoral, procura articular os temas em saúde de modo interdisciplinar, dialético e relacional. Baseia-se constantemente na complexidade e na interconexão com os saberes emanados de situações do espaço e da realidade local - global (OLIVEIRA; OLIVEIRA; VOSGERAU, 2011).

O curso de graduação em Saúde Coletiva, a fim de formar o estudante de maneira integral e sistêmica, tem como metodologia de ensino o trabalho por projetos, centrando-se na resolução de problemas, introduzindo uma dinâmica integradora e de síntese entre a teoria e a prática (idem, 2011). A teoria surge da prática, tal como esta daquela, num processo interativo e colaborativo, não havendo separação entre o saber e o saber fazer. Assim, integra conhecimentos adquiridos e desencadeia a construção de novos conhecimentos e experiências. Pela prática se humaniza, se socializa o saber; a teoria ajuda a ultrapassar o empirismo, estrutura e aprofunda esse saber.

Além do desenvolvimento científico, cognitivo e técnico, a matriz curricular contempla o estímulo dos aspectos afetivos e sociais, em uma perspectiva emancipatória e de protagonismo de seus sujeitos. A partir da abordagem de desenvolvimento integral do educando, apóia-se nos quatro pilares da educação estabelecidos pela Comissão Internacional sobre a Educação para o século XXI, em 1996, no documento intitulado "Educação: um tesouro a descobrir" (DELORS, 2003) : (a) Aprender a conhecer, isto é adquirir os

(ALENCASTRO, 2009:59). Pressupõe-se que o estudante tendo uma motivação pessoal que lhe impulsione a investigação, o desenvolvimento de sua autonomia perante o conhecimento será uma consequência. Geralmente os PAs são desenvolvidos em duplas de estudantes que se auto-apóiam durante todo o processo, que pode ter a mesma duração do curso ou não. Incentiva-se também a articulação entre Teoria e Prática, através da intervenção na realidade local a partir do tema investigado.

6 ICH (Interações Culturais e Humanísticas): "São atividades que promovem a interação vertical (estudantes em fases diferentes dos cursos) e horizontal (estudantes de cursos diferentes no mesmo espaço). Nessas Interações, construídas simétrica e dialogicamente entre estudantes, comunidades e servidores, são valorizados os diferentes saberes e lugares culturais que compõem a vida social. Os saberes são problematizados, fortalecendo compromissos éticos e políticos, visando à vivência e o adensamento de relações autogestionárias" (Disponível em: http://www.litoral.ufpr.br/ich).

7 Segundo Delors (2003, p. 102), além de aprender a conhecer que é "adquirir o domínio dos instrumentos do conhecimento que favorece o despertar da curiosidade intelectual, estimula o sentido crítico, com autonomia

Divers@Revista Eletrônica Interdisciplinar/Matinhos/ Vol.5,n.1/p.1-92//jan./jun.2012 
instrumentos da compreensão; (b) Aprender a fazer, para agir e interagir com o meio envolvente;(c) Aprender a viver juntos, a fim de participar e cooperar com os outros em todas as atividades humanas e (d) Aprender a ser, via essencial que integra as três precedentes.

Inserido no contexto pedagógico do curso de graduação em Saúde Coletiva, o objetivo deste trabalho foi relatar a experiência do módulo 'resolução alternativa de conflitos' e discutir teórica e metodologicamente os conceitos e práticas da humanização e autoconhecimento inseridos numa proposta de currículo inovador que integra ensino/pesquisa e extensão.

\section{Contexto e Objetivos}

Este módulo surge a partir da necessidade real de mediação de conflitos internos e externos estabelecidos entre os estudantes de uma turma do curso de graduação em Saúde Coletiva da Universidade Federal do Paraná Setor Litoral. O trabalho por projetos pressupõe tornar as experiências vivenciadas no real um momento pedagógico significativo para a compreensão dos conceitos relevantes para a formação profissional e pessoal. Neste sentido, consideramos propício aproveitar os conflitos que emergiram na turma para introduzir o tema, que além de já estar previsto na matriz curricular do curso, também possibilitaria habilitar os educandos para atuarem futuramente em equipes multiprofissionais e mediarem conflitos relacionados ao campo de atuação profissional, social e pessoal.

Neste módulo, diferente da maioria das disciplinas de Resolução e Mediação de Conflitos ofertada em cursos de graduação e especialização, que tem comumente um objetivo meramente conceitual como apresentar as teorias de conflito e as estratégias de resolução mais usuais (negociação, mediação e arbitragem, entre outras), tínhamos como objetivo geral oferecer uma dinâmica mais vivencial que privilegiasse a subjetividade dos estudantes, envolvendo atividades e discussões sobre o autoconhecimento e a responsabilidade dos sujeitos pelas suas escolhas e ações na interação com seus pares na vida cotidiana (família, trabalho, relações afetivas, entre outras).

e capacidade de aprender" e "do aprender a fazer que denota o enfrentamento das situações cotidianas, o trabalho em equipe, o cultivo das qualidades humanas e as relações interpessoais", as atitudes que devem nortear a prática dos futuros profisssionais devem incorporar o "aprender a ser e aprender a viver juntos, que pressupõem "a compreensão do outro e a percepção das interdependências [...] no respeito pelos valores do pluralismo e da compreensão mútua".

Divers@Revista Eletrônica Interdisciplinar/Matinhos/ Vol.5,n.1/p.1-92//jan./jun.2012 
A opção por essa forma de abordagem baseou-se principalmente na concepção do Projeto Político Pedagógico da UFPR - Setor Litoral que pretende desenvolver profissionais que tenham além da formação técnica, também uma formação integral humana livre de posturas rígidas e mecânicas marcadas pelo medo, desconfiança e outros sentimentos negativos que são improdutivos e desastrosos para a convivência social harmoniosa. $\mathrm{O}$ educando deve aprender a responder pelos seus atos, deve ser consequente nas suas ações, assumindo a responsabilidade pelo que faz ou deixa de fazer. Lembramos aqui o sentido da palavra competência no relatório de Jacques Delors: ao invés de só acumular conhecimentos, o mais importante é estar apto para aproveitar as oportunidades de aprofundar e enriquecer os primeiros conhecimentos num mundo que está em acelerada mudança (DELORS, 2003).

\section{Metodologia}

Este relato de experiência está pautado na observação participante dos docentes envolvidos, análise de documentos produzidos por estudantes e professores da rede básica de educação e relatos orais das experiências vivenciadas no módulo de 'Ciências sociais e humanas II: Resolução alternativa de conflitos'.

Foram participantes do módulo os estudantes da turma 2010 do Curso de Saúde Coletiva, sendo que a grande maioria $(80 \%)$ era do sexo feminino e professoras do ensino superior e médio com formação em: Linguística Aplicada, Desenvolvimento Psicossocial, Saúde Coletiva e Língua Portuguesa. Nossa participação não se deu somente como mediadoras do processo, mas também como observadoras-participantes porque como educadoras, somos formadoras de opinião e, portanto, parte da realidade com a qual estávamos lidando.

O tempo de duração do módulo foram 40 horas, divididos em 7 encontros desde maio até junho de 2011. As dinâmicas pedagógicas utilizadas foram teatro, filmes, dinâmicas em grupo, leitura de textos, música e atividades de autoconhecimento. Utilizou-se como referencial teórico das discussões, mais especificamente o conceito de Sombra da psicologia analítica de Carl Gustav Jung e outros autores junguianos (ZWEIG, ABRAMS, 2009), o fundamento do modelo da teoria U de C. Otto Scharmer (SCHARMER, 2010), as principais ideias do Teatro do Oprimido de Boal (1980), os pressupostos da educação para o futuro de Jacques Delors (DELORS, 2003), o PPC do curso de Graduação em Saúde Coletiva (UFPR,

Divers@ Revista Eletrônica Interdisciplinar/Matinhos/ Vol.5, n.1/p.1-92//jan./jun.2012 
2011) e PPP da UFPR Setor Litoral (UFPR, 2008). A avaliação do módulo se deu por meio de autoavaliação (falas e relatos escritos) e heteroavaliação coletiva e individual.

\section{Abordagens pedagógicas utilizadas no módulo: Conceitos e discussão dos resultados observados}

\section{Primeira abordagem: Teatro do Oprimido de Augusto Boal (1980)}

A primeira técnica utilizada no módulo de forma a identificar que conflitos os alunos da turma de 2010 do curso de graduação de Saúde Coletiva estavam vivenciando foi a técnica teatral. A técnica de teatro utilizada foi baseada no Teatro do Oprimido de Augusto Boal (1980) que utiliza jogos e técnicas teatrais a fim de problematizar uma situação cotidiana vivenciada por pessoas de um determinado grupo para que possam identificar e refletir sobre as relações de poder envolvidas em uma determinada situação. De acordo com Boal (1980) “o teatro pode ser uma arma de libertação, de transformação social e educativa". Através da dramatização de uma situação-problema pertinente a esta turma, os participantes puderam visualizar, vivenciar, perceber e refletir os aspectos pessoais, sociais e culturais, bem como as relações de poder envolvidas na situação de conflito emergente. Tanto os sujeitos envolvidos na dramatização como os estudantes que estavam na platéia puderam observar a situação e visualizar as relações de conflito. Como professoras, exercemos o papel de mediadoras a fim de incentivar a platéia a identificar os conflitos, como também substituir os alunos-atores da cena inicial para recriá-la com o objetivo de encaminhar reflexões e possibilidades de soluções para o conflito ou os conflitos identificados.

Ao repetirem as dramatizações, os alunos-atores apresentaram dificuldade em solucionar o conflito identificado pelo grupo. Como professoras-mediadoras e participantes do processo, observamos que a turma, de forma geral, demonstrou certa resistência em resolver o conflito apresentado, e quando um determinado conflito era solucionado ou amenizado, os alunos-atores introduziam um novo conflito à cena. Este novo conflito era geralmente sugerido e/ou apoiado pelos alunos da platéia. Esta observação é muito significativa e intrigante, pois pela experiência de aplicação da mesma técnica com outros grupos, os participantes tendem a encaminhar a solução do conflito logo nas primeiras cenas.

Divers@Revista Eletrônica Interdisciplinar/Matinhos/Vol.5, n.1/p.1-92|/jan./jun.2012 
Neste grupo a atenção e a intenção dos conflitos internos era tão evidente que impedia a escuta sensível ${ }^{8}$, a ponto dos participantes ignorarem o objetivo da dinâmica, que foi estabelecido claramente no início da atividade, ou seja, resolver o conflito dramatizado. Como a escuta sensível se apóia na empatia e no reconhecimento e aceitação incondicional do outro, este processo reiterou a importância de refletir sobre a qualidade interior do indivíduo que intervém na realidade porque esta é determinante no resultado final de qualquer ação. De acordo com Cristina D'Arce, coordenadora da Society for Organizational Learning Brasil $\left(\right.$ SOL Brasil) ${ }^{9}$,

Os projetos de educação devem trabalhar os modelos mentais porque a mudança depende muito das faculdades internas do indivíduo e do modo como ele olha o mundo. Essa transformação interior, no fundo, é o que realmente vai fazer diferença nos diálogos. Enquanto os líderes verem a sustentabilidade apenas como mais um business, a discussão não avançará. (Disponível em: www.ideiasocioambiental.com.br).

De acordo com Otto Sharmer, autor do livro "Teoria U: como liderar pela percepção e realização do futuro emergente", é muito importante sabermos a condição interior dos líderes quando eles agem, porque o sucesso ou insucesso depende da qualidade de atenção que trazem para a situação em que intervém. Segundo Sharmer, para fazer frente aos desafios urgentes de nosso tempo, as pessoas em geral, mas principalmente os líderes, precisam parar de fazer download, isso é, "baixar" antigos padrões baseados em experiências do passado, porque essas ferramentas já não são mais capazes de nos ajudar a resolver os problemas contemporâneos. "É preciso desacelerar e aprender a escutar de forma mais profunda, mais aberta e mais coletiva", com a mente aberta, o coração aberto e a vontade aberta (SHARMER: 2010). Em outras palavras, as pessoas precisam ter consciência de seu "ponto cego" que nada mais é do que os padrões rotineiros de pensamento e ação. $\mathrm{O}$ caminho proposto pelo autor na Teoria U segue o próprio desenho da letra U e consiste de três grandes movimentos: descer

8 De acordo com Roberto Crema, para cuidar, precisamos escutar e só escuta realmente quem é capaz de silêncio interior. "A escuta não-projetiva é um bem precioso e raro, dos que cultivam a mente meditativa e contemplativa, nas trilhas do despertar para o Instante, a pátria da Presença” (CREMA, 2002:149).

9 No início da década de 90, nos EUA, um grupo de empresas e o Massachussets Insitute of Technology, MIT, começou a realizar pesquisas e experimentos com o propósito de desenvolver um campo de conhecimento denominado Aprendizagem Organizacional. A SOL (Center for Organizational Learning), instituição ligada ao MIT, foi criada em 1997 e deu continuidade aos trabalhos iniciados por Peter Senge (autor do livro "A Quinta Disciplina"). Ao longo dos anos, formou-se em torno dela uma grande comunidade com representantes de mais de 30 países que congrega hoje as pesquisas e experiências mais inovadoras nas áreas de aprendizagem organizacional, pensamento sistêmico e sustentabilidade (www.ideiasocioambiental.com.br).

Divers@Revista Eletrônica Interdisciplinar/Matinhos/ Vol.5,n.1/p.1-92//jan./jun.2012 
um lado do U (parar o dowloading, deixar ir o antigo, desacelerar, observar, observar e observar, ficar no agora), conectar-se com a fonte (aquietar-se, ficar em silêncio, meditar) e subir o outro lado do U (deixar emergir o novo, cristalizar a intenção que surge desse contato com o EU autêntico, prototipar e desempenhar o novo colocando-o em prática), conforme figura abaixo:

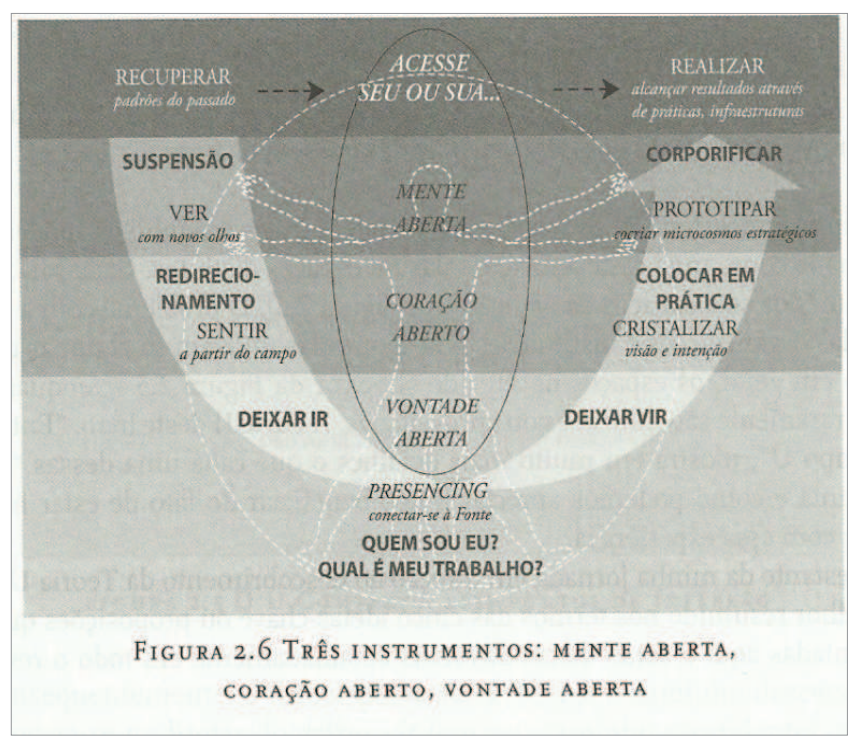

Fonte: http://pensandosustentabilidade.blogspot.com

Era isso que os estudantes estavam fazendo quando resistiam e persistiam em perpetuar o conflito: estavam fazendo o download, isto é, reproduzindo automaticamente os velhos padrões de pensamento e ação que aprenderam. Ao percebermos essa resistência na turma, encaminhamos a discussão no sentido dos participantes perceberem como estavam recriando o conflito, conectando-se uns aos outros de forma defensiva e reativa. Precisávamos mostrar outro modelo de conexão: o dialógico e generativo que pressupõe a mente aberta, coração aberto e vontade aberta. Desta forma, foram necessárias várias dramatizações e reflexões para que estes compreendessem que não estavam solucionando o conflito e sim, o tornando ainda mais complexo. A partir destas observações mencionadas, foram introduzidos outros conceitos e técnicas a fim de instigar nos estudantes a percepção de que os sujeitos e organizações precisam deixar de 'fazer' a mudança, para 'ser' a própria mudança e, para tanto, devem aprender quais os fatores envolvidos nesta resistência de solução de conflitos e como estão reproduzindo-os. Para chegar a este termo, introduzimos o conceito junguiano de

Divers@ Revista Eletrônica Interdisciplinar/Matinhos/Vol.5, n.1/p.1-92|/jan./jun.2012 
Sombra e, como técnica para facilitar a auto-observação e eliminação das dificuldades emocionais de lidar com situações conflituosas, a (EFT) Técnica de Libertação Emocional.

\section{Segunda abordagem: Conceito de sombra de Carl Gustav Jung}

O principal objetivo de trabalhar o conceito de sombra de Carl Gustav Jung com os estudantes neste módulo foi o de refletir sobre a necessidade e importância da integração da personalidade. Integrar aquilo que nos parece inferior e que foi sendo empurrado para o inconsciente, excluído de nossa vida, para que possamos ampliar nossa experiência e assumir a responsabilidade por isso.

Uma frase conhecida de Jung "Ninguém se torna iluminado imaginando figuras de luz, mas tornando a escuridão consciente" foi a ideia que nos inspirou para trabalhar com esse conceito, porque acreditamos que o primeiro passo para resolver nossos problemas é assumindo que somos parte deles. Através de uma brincadeira com a frase constantemente mencionada pelo personagem Homer Simpson, desenho veiculado pelo canal Fox de TV à cabo, "eu poderia me culpar, mas é mais fácil culpar os outros" 10 , foi introduzido o conceito de projeção ${ }^{11}$ que está diretamente ligado ao conceito de sombra.

Quando os sujeitos não conseguem lidar com emoções difíceis ou partes inaceitáveis de sua personalidade, estas podem ser projetadas em outra pessoa ou em um objeto externo. Considerando que a sombra trata-se desse lado negativo da personalidade, a soma de todas as qualidades desagradáveis que o sujeito quer esconder, seu lado obscuro, ou ainda, nas palavras do próprio Jung "a coisa que uma pessoa não tem desejo de ser", é compreensível que todos nós tenhamos a necessidade de rejeitar esse lado incompatível com a Persona ${ }^{12}$ e com os padrões ideais do meio social onde vivemos. Todos nós sabemos o bem-estar provisório e a libertação efêmera que sentimos quando passamos a responsabilidade de assumir nossos problemas aos outros. Entretanto, além dessa sensação prazerosa ser

10 A outra versão da frase também comumente mencionada pelo personagem Homer Simpson é: "Seria muito fácil me culpar, mas é mais fácil culpar os outros".

11 Quem introduziu o termo "projeção" em Psicologia foi Sigmund Freud mencionando-o pela primeira vez em 1884 (FREUD, 1948). A projeção acontece quando a pessoa projeta suas qualidades indesejáveis em outra(s) pessoa(s), não conseguindo perceber que todos os defeitos apontados no outro, estão nela mesma.

12 Jung define a persona como "... o sistema individual de adaptação para o mundo. Toda vocação, profissão ou papel social, por exemplo, tem a sua própria persona característica. Pode-se dizer, com pouco de exagero, que a persona é aquilo que na realidade não é, mas tanto si mesmo, quanto os outros acham que é" (CW9, $\left.\mathrm{n}^{\circ} 221\right)$.

Divers@ Revista Eletrônica Interdisciplinar/Matinhos/Vol.5, n.1/p.1-92|/jan./jun.2012 
passageira, o nosso lado Sombra não pode ser simplesmente abolido do nosso ser, porque ele é parte integral de nossa natureza humana que é dual e torna-se muito mais perigoso quando não é reconhecido pelo seu portador.

Além disso, uma pessoa sem Sombra é uma pessoa que negligenciou uma parte importante de sua força interior e, por isso, fica incompleta. O poeta Fernando Pessoa, em sua poesia "Ser Inteiro", já alertava que para sermos seres autênticos devemos resguardar nossa ambivalência.

\author{
Ser Inteiro \\ (Fernando Pessoa) \\ Para ser grande, sê inteiro: \\ Nada teu exagera ou exclui. \\ Sê todo em cada coisa. \\ Põe quanto és \\ no mínimo que fazes. \\ Assim em cada lago a lua toda brilha, \\ porque alta vive.
}

Carl Gustav Jung também era perfeitamente consciente da realidade do Mal na vida humana, inclusive num primeiro momento pressupunha que a Sombra era a fonte natural de todo o mal. Porém, a investigação do inconsciente humano demonstrou que a Sombra não é constituída somente de tendências moralmente condenáveis, mas também de qualidades positivas, a exemplo dos instintos normais que se compõem de reações necessárias à sobrevivência, bem como os impulsos criativos e outros (JUNG, 1976). Numa definição mais tardia, Jung ressaltou que a sombra é também sede da criatividade, racionalidade, força e outras boas qualidades da psique humana, sem deixar de ponderar que os maus aspectos da sombra são de fato esmagadores. Qual a saída então? Concordando com Jung ${ }^{13}$, em nossa opinião a melhor situação para lidar com o lado sombra da natureza humana é o autoconhecimento da psique. Dizemos isso porque, além do que já foi falado acima que a sombra também tem qualidades positivas como a força, a criatividade, enfim, devemos ter sob controle aquilo que nos deixa em perigo ou como diz Debbie Ford no filme "O Efeito Sombra": "ou você domina seu lado sombra ou seu lado sombra o dominará". Se uma inferioridade é consciente, sempre se tem uma oportunidade de corrigi-la, ou melhor ainda, utilizá-la em situações que precisam daquela qualidade.

13 Jung acreditava que o autoconhecimento seria a única forma do homem ser capaz de minimizar o mal que faz parte da formação da natureza psíquica do ser humano, ou, quem sabe, até acabar finalmente com os conflitos causados pelos instintos primitivos.

Divers@ Revista Eletrônica Interdisciplinar/Matinhos/Vol.5, n.1/p.1-92|/jan./jun.2012 
E qual a melhor maneira de trazer para a consciência essas qualidades consideradas negativas que queremos fazer funcionar a nosso favor e não deixar que quando estivermos numa conjuntura desfavorável entremos em colapso? A maneira mais fácil é o autoconhecimento, que é consequência direta da auto-observação. Ao reconhecer que aquelas características que mais nos aborrecem no comportamento dos outros e que costumamos apontar com o dedo em riste, vem de fato de nós mesmos, facilita bastante a tolerância e o respeito à divergência de opiniões e ações. Há um ditado famoso muito utilizado na literatura de espiritualista que diz: "àquilo que você resiste, persiste".

Assumir nossas dificuldades, nesta perspectiva, não seria uma fraqueza. Ao contrário, o autoconhecimento da própria psique representaria um aumento de sabedoria e não só de conhecimento como tem feito o homem moderno, pois para uma mudança social desejável que pouparia muito sofrimento às pessoas, estas devem conhecer sua própria capacidade de fazer o bem e também o mal. Na medida em que nos tornamos mais conscientes de nossa realidade interior, a camada do inconsciente pessoal que recobre o inconsciente coletivo será reduzida, emergindo uma consciência emancipada do mundo individualista refém da vontade pessoal do Eu, tornando-se livre para participar dos interesses da coletividade.

Sem aprofundarmos mais essa discussão que não é nosso intuito nesse texto, pois o objetivo é justificar as estratégias e abordagens conceituais utilizadas no módulo "Resolução Alternativas de Conflitos", colocamos uma citação de Jung que exalta o bom senso da mesma maneira que Fernando Pessoa quando diz "nada teu exagera ou exclui":

O mal tem que ser ponderado, tanto quanto o bem, afinal, o bem e o mal não são extensões de um ideal e de fazer abstrações, ambos pertencem ao 'claro-escuro' da vida... em última instância, não há nenhum bem que não possa produzir o mal e nenhum mal que não possa produzir o bem (JUNG, 1971:31).

\section{Terceira abordagem: reflexão e prática de autoconhecimento}

Após discutir nossa responsabilidade nos conflitos que estamos envolvidos através do conceito de sombra, aonde vimos que todos nós somos seres ambivalentes, aptos a fazer tanto o bem quanto o mal, decidimos introduzir uma dinâmica de grupo onde todos nós fossemos capazes de perceber algo de bom nos outros participantes, mesmo entre aqueles que já se havia decidido serem incompatíveis para manterem uma relação amigável.

Divers@ Revista Eletrônica Interdisciplinar/Matinhos/Vol.5, n.1/p.1-92//jan./jun.2012 
$\mathrm{Na}$ terceira abordagem enfatizamos ainda mais a necessidade do autoconhecimento. Para tanto, realizamos atividades durante as 4 horas/aula, divididas em dinâmicas de grupo, socialização das impressões dos professores e estudantes que participaram do momento e rodagem do filme 'Poder além da vida' com posterior roda de conversa e debate sobre temas como: poder interior, autoconhecimento e sabedoria, consciência das escolhas individuais, amor, auto-estima e determinação. Ao final, foi solicitado que todos escrevessem uma carta para si próprios com as reflexões sobre quem cada sujeito gostaria de ser e onde gostaria de estar daqui há 1 ano, 5 anos e 10 anos e quais ações, mudanças, transformações seriam necessárias para a realização efetiva e sincera dos sonhos de cada um. Esta carta foi entregue às professoras organizadoras do módulo e serão enviadas aos educandos após passado 1 ano desse módulo.

$\mathrm{Na}$ dinâmica de grupo 'Aprendendo a perceber o outro' foi solicitado que os participantes descrevessem uma qualidade positiva de cada um dos integrantes da turma. Ao final, todas as pessoas tinham uma lista extensa das qualidades que os outros percebem nela. Interessante foi notar que, apesar de 1 ano de convivência entre eles, haviam ainda estudantes que não conheciam sequer o nome do(a) colega de turma. As questões que surgiram foram problematizadas à luz de conceitos de identidade, alteridade, humanização, respeito às necessidades do próximo e capacidade de percepção positiva das pessoas que compõem os grupos sociais dos quais fazemos parte.

Para pensar e debater qual o propósito de vida de cada um, isto é, o que fazer, como fazer, mas principalmente o para quê fazer na perspectiva de ter um sentido para a atuação pessoal e profissional, introduzimos o filme "Poder além da vida". Neste filme que conta a história de um talentoso ginasta adolescente chamado Dan Millman, o personagem principal busca aprovação externa, reage ao controle dos outros sem se questionar por que faz o que faz. Busca a perfeição e tenta corresponder às exigências, mas com isso oculta seus próprios conflitos internos. A partir dos questionamentos de Sócrates, seu treinador e mestre espiritual, o atleta passa a refletir sobre quem é ele realmente na essência e quais são seus valores. Em outras palavras, Dan fazia tudo automaticamente e quando foi pressionado para uma reavaliação interior, iniciou um processo de autotransformação que acabou por refletir em sua vida social e profissional.

O homem está em um processo contínuo de transformação. O homem cria, constrói e, ao mesmo tempo, é transformado e construído por suas próprias ações. O autoconhecimento

Divers@Revista Eletrônica Interdisciplinar/Matinhos/ Vol.5,n.1/p.1-92//jan./jun.2012 
nos leva a um processo intenso de interiorização, nos fazendo compreender por que agimos e reagimos a uma determinada situação. Desta maneira, tornamo-nos capazes de fazer escolhas mais conscientes, e que consequentemente nos levará à maior satisfação e descoberta de um sentido da vida mais significativo.

Entretanto, desde a primeira infância, somos criados para construir "máscaras" e proteger nossa verdadeira essência. Fomos adquirindo padrões sócio-culturais que quando são rígidos e inflexíveis bloqueiam nosso processo de desenvolvimento. Neste contexto, quanto mais a pessoa se conhece, menos faz projeções sobre os outros, mais pode se relacionar consigo mesma e com as outras pessoas de maneira objetiva, genuína e sem ilusões. Assim, abordar o tema autoconhecimento foi de suma importância para o processo de ensinoaprendizagem da mediação e soluções de conflitos emocionais e sociais, pois desta forma possibilitou aos educandos conhecerem mais sobre eles próprios e sobre outros sujeitos participantes desta realidade.

O grande desafio posto é que todos os sujeitos que participaram destes encontros fossem capazes de transformar antagonismos em convergências relacionais, mesmo que na prática não sejam concordantes. O autoconhecimento e a autoavaliação são caminhos seguros para aumentar as ferramentas emocionais e cognitivas em processos de mediação e resolução de situações violentas, dissoantes e conflitantes.

\section{Quarta abordagem: EFT (Técnica de libertação emocional)}

Outra técnica apresentada aos participantes desse módulo foi a Técnica de Libertação Emocional. A EFT - Emotional Freedom Techniques ou em português - Técnica de Libertação Emocional, também conhecida como acupuntura sem agulhas, é uma técnica que foi desenvolvida pelo engenheiro norte-americano Gary Craig, baseado nas descobertas realizadas pelo Psicólogo americano Dr. Roger Callahan (Disponível em: www.eftbr.com.br). O método está fundamentado na ideia de que "a causa de todas as emoções negativas é uma interrupção no fluxo energético do corpo" e consiste no desbloqueio dos canais energéticos, que são chamados de meridianos, enquanto o indivíduo se sintoniza (fala) em um problema emocional ou físico. Esses meridianos são os mesmos estudados pela Acupuntura e pode-se dizer que a EFT é uma "versão emocional” desta outra técnica.

Divers@Revista Eletrônica Interdisciplinar/Matinhos/Vol.5, n.1/p.1-92//jan./jun.2012 
Enquanto na psicoterapia convencional, que "trata das memórias", presume-se que as lembranças traumáticas do passado sejam a causa direta da confusão emocional em alguém, na EFT, pressupõe-se que existe um passo intermediário, uma peça entre a lembrança e a confusão emocional, que é a interrupção no fluxo energético do corpo, causando um desequilíbrio que pode ocasionar tanto doenças físicas quanto doenças psico-emocionais.

A EFT segue a mesma abordagem da MTC - Medicina Tradicional Chinesa sobre o corpo humano, ou seja, de que embora este pareça sólido, é na realidade composto de energia sutil $^{14}$. Sendo assim, o corpo humano é atravessado por meridianos que são formados por uma rede de dutos (canais) microscópicos organizados e que conectam os órgãos internos com a função de transportar a energia através de todo o organismo. O sistema de meridianos transfere do ambiente para os nervos, vasos sanguíneos e glândulas endócrinas a energia sutil através de portais energéticos - os chakras. Cada meridiano é formado por um número de pontos que transmitem a energia em sentido e ordem sempre constantes ${ }^{15}$. Quando há uma reversão no sistema energético, pode-se dizer que a pessoa está se auto-sabotando. De acordo com André Lima ${ }^{16}$ :

Segundo os conceitos que envolvem as teorias da EFT quando nosso sistema energético está revertido em relação a algum problema, nós nos auto-sabotamos consistentemente. Isso acontece muito em casos de vícios, perda de peso, depressão, entre outros problemas. O que acontece é que, racionalmente a pessoa quer, sabe o que é melhor fazer, mas seu sistema energético, ou seja, sua resposta emocional inconsciente lhe diz para fazer justamente o contrário (Manual de EFT).

O fundamento da EFT está baseado na ideia de que em muitos casos de desempenho insatisfatório, geralmente está presente alguma emoção negativa: raiva, ansiedade, medo, ressentimento. Em outras palavras, as emoções negativas impedem a pessoa de dar o melhor de si, faz com que ela se auto-sabote.

O conceito de auto-sabotagem é bastante interessante para a resolução de conflitos, porque é comum que conflitos interpessoais sejam ocasionados por uma reação emocional, a qual na maioria das vezes é inconsciente, a pessoa não sabe por que age de determinada

14 Segundo diversas escolas espiritualistas (Teosofia, Rosa-Cruz, Projeciologia, Yoga, Espiritismo, etc.), existe uma forma de energia sutil (também conhecida como energia cósmica, prana, éter cósmico, ch’i) que permeia o espaço e toda a matéria existente na Natureza.

15 A Organização Mundial de Saúde (OMS) reconheceu cerca de 400 pontos de Acupuntura e 20 meridianos conectando a maioria dos pontos. Os pontos e meridianos de Acupuntura são comumente reconhecidos por possuírem propriedades elétricas diferenciadas.

16 André Lima é EFT Practitioner e um dos palestrantes pioneiros no Brasil e na apresentação de workshops de EFT. Ele mantém um site que as pessoas podem acessar para ler artigos, tirar dúvidas e, inclusive, marcar horário para uma sessão de EFT on-line pelo skype. Acesse: www.eftbr.com.br.

Divers@Revista Eletrônica Interdisciplinar/Matinhos/ Vol.5,n.1/p.1-92//jan./jun.2012 
maneira. Conforme SCARF, a transição de um problema intrapsíquico para um conflito interpessoal acontece através da identificação projetiva, ou seja, "envolve a projeção dos aspectos negados e reprimidos da experiência interior de uma pessoa sobre o seu parceiro íntimo" (in: ZWEIG e ABRAMS, 2009:97), por exemplo. Com o conhecimento da prática dessa técnica, o sujeito ao se deparar com uma situação de conflito poderá fazer uma autoaplicação e tentar descobrir o porquê de sua reação, isto é, quais crenças ou emoções negativas inconscientes desencadearam sua reação. É muito comum que as pessoas, após a aplicação da técnica, tenham uma nova percepção da ocorrência, muitas vezes até defendendo a outra pessoa envolvida com frases do tipo: "ela não tem culpa"... "eu agora entendo porque ela fez isso".... “coitado, deixa prá lá, ele está passando por uma fase difícil”, etc.

Nesse sentido, a EFT tem como objetivo capacitar as pessoas para terem liberdade emocional, removendo as emoções e crenças negativas, pois mesmo quando há dor, por trás existe uma emoção que bloqueou o sistema de circulação de energia.

A EFT é aplicada através da estimulação de pontos de acupuntura (meridianos), com batidas leves das pontas dos dedos (chamadas de "tapping"), ao mesmo tempo em que a pessoa vai falando sobre o problema que a aflige. Os pontos de acupuntura que usamos durante o módulo foram só alguns, o chamado "atalho", pois são muitos os pontos, mas esses por si só já resolvem quando utilizados. Abaixo duas figuras prá demonstrar quais foram esses pontos. A primeira figura é o ponto do karatê. Sempre se começa a técnica por esse ponto dizendo três vezes a frase de preparação: "Mesmo que eu (tenha esse problema, pode ser dor ou problema emocional, raiva) eu me aceito profunda e completamente".

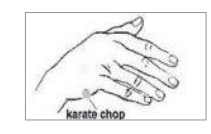

PONTOS DO ATALHO:

PGK $=$ Ponto golpe do karatê

PTC $=$ Ponto topo da Cabeça

PIS= Ponto início da Sobrancelha

PLO $=$ Ponto do Lado do Olho

$\mathrm{PEO}=$ Ponto embaixo do Olho

$\mathrm{PEN}=$ Ponto embaixo do Nariz

$\mathrm{PEB}=$ Ponto embaixo da Boca

$\mathrm{POC}=$ Ponto osso Clavícula

$\mathrm{PEA}=$ Ponto embaixo da Axila

Divers@Revista Eletrônica Interdisciplinar/Matinhos/Vol.5, n.1/p.1-92//jan./jun.2012 


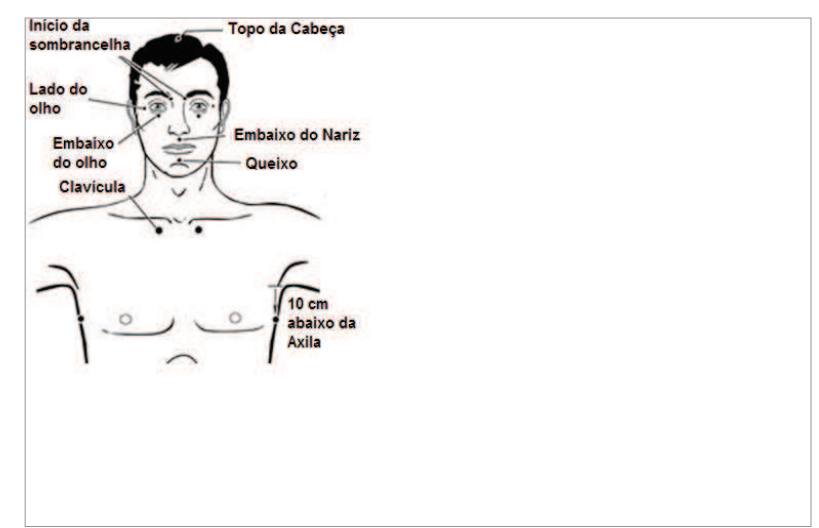

Fonte: Dione Lorena Tinti - Desenho realizado para utilizar em sala de aula.

Resumindo, o principal motivo de termos introduzido a técnica de EFT no módulo foi para ensiná-la porque além de simples para aprender e ser bastante eficaz mesmo quando auto-aplicáve ${ }^{17}$ (depois que se aprende, pode-se aplicá-la sozinho sem a intermediação de um profissional), é um instrumento que possibilita os sujeitos livrarem-se de problemas psicossociais (conflitos pessoais e interpessoais) e desenvolverem a autonomia para fazer escolhas diante das oportunidades sem cair na reprodução social da família e do grupo.

A técnica foi aplicada em sala de aula para que os estudantes, além de terem a parte teórica, também tivessem acesso ao lado prático da técnica, observando a aplicação em uma das estudantes que foi voluntária.

\section{Considerações finais}

Nossa intenção neste trabalho foi demonstrar que é possível trabalhar as faculdades internas dos nossos educandos e de como eles percebem o mundo, a partir de estratégias em sala de aula que questionem os modelos mentais que têm orientado as intenções e ações insensíveis aos problemas do convívio humano. Salientamos que não refletimos suficientemente a respeito do fim de nossas ações, porque na maioria das vezes, sabemos $o$ que fazer, como fazer, mas perdemos de vista o para que fazer.

Reforçamos aqui a ideia de que para atingir o objetivo de formar nossos futuros profissionais para serem autônomos, competentes, sensíveis e solidários, o desafio é ir além da aprendizagem do aprender a conhecer e aprender a fazer, orientação principal ainda de

17 Mesmo que só uma das partes da relação conflituosa conheça e aplique a técnica já é o suficiente. Como diz um antigo ditado popular "quando um não quer, dois não brigam”.

Divers@ Revista Eletrônica Interdisciplinar/Matinhos/Vol.5, n.1/p.1-92//jan./jun.2012 
grande parte das instituições educacionais atuais. Seguindo a ideia de Delors (2003) de que é preciso desenvolver também a Competência Pessoal (aprender a ser) e a Competência Social (aprender a conviver), desenvolvemos estratégias em sala de aula que proporcionassem a revisão de conceitos e práticas de ação não desejáveis. Através de encenação teatral de situações de conflito, do conceito psicanalítico de sombra de Jung, de filmes, de dinâmica de identificação de qualidades positivas entre os participantes e de uma técnica de identificação e liberação de emoções negativas, foram desconstruídos e reconstruídos conceitos e práticas baseadas no não-julgamento do outro e na comunicação não-violenta.

Percebemos que o uso destas abordagens pedagógicas ao longo do módulo 'resolução alternativa de conflitos' no curso de Saúde Coletiva permitiu aos envolvidos identificar, compreender e saber lidar com as emoções negativas numa perspectiva sistêmica. A desconstrução/reconstrução dos conceitos e práticas se sustentou nos temas: não-julgamento do outro, autoconhecimento, comunicação não-violenta e consciência sobre o bem e o mal, nosso lado sombra.

Salientamos que os momentos grupais levaram os sujeitos a valorizar o processo de autoconhecimento e a novos questionamentos sobre as questões psico-sócio-ambientais conforme relatos e reflexões escritas na avaliação do módulo. De modo geral, os participantes relataram que as reflexões feitas durante o módulo contribuíram para: "auto-reflexão e autoconhecimento", "percepção de nossas ações e dos problemas para melhor administrá-los", "contribuiu na nossa vida acadêmica e pessoal", "auto-aceitação e tolerância com as dificuldades do outro", "entender nossos conflitos interiores", "entender melhor as pessoas em nosso ambiente de trabalho". Vimos emergir também afinidades nas vivências, ou seja, os participantes perceberam que todos têm problemas, e que não raro, são semelhantes. A partir dessa percepção, os participantes se sentiram gratificados com trocas de saberes e o apoio mútuo nas suas necessidades emocionais.

Divers@Revista Eletrônica Interdisciplinar/Matinhos/Vol.5,n.1/p.1-92//jan./jun.2012 


\section{Referências}

ALENCASTRO, Lúcia Helena. Concepções de estudantes sobre os projetos de aprendizagem no ensino superior. [Dissertação de Mestrado]. Curitiba (PR): Universidade Federal do Paraná. Programa de Pós-Graduação em Educação, na linha de pesquisa Cognição, Aprendizagem e Desenvolvimento Humano; 2009.

ARANHA, Maria Lúcia de Arruda; MARTINS, Maria Helena Pires. Temas de Filosofia. São Paulo: Editora Moderna, 1998.

BOAL, Augusto. Teatro do oprimido e outras poéticas políticas. 2 ed. Rio de Janeiro: Civilização Brasileira, 1980.

BOFF, Leonardo. Saber cuidar: ética do humano - compaixão pela terra. Rio de janeiro: Vozes, 2003.

CHOPRA, Deepak; FORD, Debbie; WILLIAMSON, Marianne. O Efeito Sombra: encontre o poder escondido na sua verdade. São Paulo: Lua de Papel, 2010.

CREMA, Roberto. Antigos e Novos Terapeutas - abordagem transdisciplinar em terapia. Petrópolis: Vozes, 2002.

D'ARCE, Cristina. Entrevista. Disponível em www.ideiasocioambiental.com.br, acesso em 26/08/2011.

DELORS, Jacques (coord.). Educação: um tesouro a descobrir. São Paulo: Cortez, 2003.

FREUD, Sigmund. Totem e Tabu - Obras Completas. Biblioteca Nova, Madrid, 1948.

HOLLIS, James. A sombra interior: por que pessoas boas fazem coisas ruins. Osasco/São Paulo: Novo Século Editora, 2010.

JUNG, Carl Gustav. Os Arquétipos e o Inconsciente Coletivo. Petrópolis: Vozes, 1976. CW 9 i.

JUNG, Carl Gustav. Psicologia e Alquimia. Petrópolis: Vozes, 1971. CW 12.

MANUAL BÁSICO DE EFT. Disponível em: www.eftbr.com.br, acesso em 18/11/2010.

MILLMAN, Dan. O caminho do guerreiro pacífico: um livro que modifica vidas. São Paulo: Pensamento, 2009.

MILLMAN, Dan. Um novo sistema de numerologia: guia prático para você descobrir o propósito da sua vida. São Paulo: Pensamento, 2010.

MORIN, Edgar. Introdução ao Pensamento Complexo. Porto Alegre, 2005.

Divers@ Revista Eletrônica Interdisciplinar/Matinhos/Vol.5, n.1/p.1-92//jan./jun.2012 
OLIVEIRA, S.; OLIVEIRA, D.C.; VOSGERAU, M.Z.S organizadores. Projeto Pedagógico do curso de graduação em Saúde Coletiva. Matinhos: UFPR Setor Litoral, 2011.

ROSENBERG, Marshall B.Comunicação não-violenta: técnicas para aprimorar relacionamentos pessoais e profissionais. São Paulo:Editora Ágora, 2006.

SCHARMER, C. O. Teoria U: como liderar pela percepção e realização do futuro emergente. Rio de Janeiro: Elsevier, 2010.

TOLLE, Eckhart. O despertar de uma nova consciência: como reconhecer o verdadeiro propósito da sua vida e contribuir para a transformação do mundo. São Paulo: Sextante, 2007.

UNIVERSIDADE FEDERAL DO PARANÁ - Setor Litoral. Projeto político-pedagógico. Curitiba: Editora UFPR, 2008.

ZWEIG, Connie; ABRAMS, Jeremiah (orgs.). Ao encontro da sombra: O potencial oculto do lado escuro da natureza humana. São Paulo: Cultrix, 2009.

Filmes trabalhados no módulo:

O efeito Sombra: encontre o poder escondido na sua verdade. EUA, 2010, Documentário, DVD.

Poder Além da Vida. EUA, 2006, Drama, DVD. 